\title{
Needs of reliable nuclear data and covariance matrices for Burnup Credit in JEFF-3 library
}

\author{
A. Chambon ${ }^{1}$, A. Santamarina ${ }^{1}$, C. Riffard ${ }^{1}$, F. Lavaud ${ }^{2}$ and D. Lecarpentier ${ }^{2}$ \\ ${ }^{1}$ CEA, DEN, DER, SPRC, Cadarache Center, F-13108 Saint Paul-lez-Durance, France \\ ${ }^{2}$ EDF, 1 Avenue du Général de Gaulle, BP 408, F-92141 Clamart, France
}

\begin{abstract}
Burnup Credit (BUC) is the concept which consists in taking into account credit for the reduction of nuclear spent fuel reactivity due to its burnup. In the case of PWR-MOx spent fuel, studies pointed out that the contribution of the 15 most absorbing, stable and non-volatile fission products selected to the credit is as important as the one of the actinides. In order to get a "best estimate" value of the $\mathrm{k}_{\mathrm{eff}}$, biases of their inventory calculation and individual reactivity worth should be considered in criticality safety studies. This paper enhances the most penalizing bias towards criticality and highlights possible improvements of nuclear data for the 15 FPs of PWRMOx BUC. Concerning the fuel inventory, trends in function of the burnup can be derived from experimental validation of the DARWIN-2.3 package (using the JEFF3.1.1/SHEM library). Thanks to the BUC oscillation programme of separated FPs in the MINERVE reactor and fully validated scheme PIMS, calculation over experiment ratios can be accurately transposed to tendencies on the FPs integral cross sections.
\end{abstract}

\section{Introduction}

The issue of the acceptability by the Safety Authority of the sub-criticality demonstration of nuclear industrial facilities and applications is based on a criticality-safety study taking into account the most penalizing hypothesis. During the operation, the subcriticality in any situation is guaranteed by the respect of the Under Subcritical Limit for the calculated $\mathrm{k}_{\text {eff. }}$.

Considering spent fuel management (storage, transportation, reprocessing), the approach using "fresh fuel assumption" results in a significant conservatism in the calculated value of system reactivity. The concept of taking credit for the reduction of the reactivity of spent fuel due to the reduction of net fissile content, build-up of actinides and increase of fission products concentration is referred to as "Burnup Credit" (BUC) [1]. Allowing reactivity credit for spent fuel offers many economic incentives.

Recent publications and discussions within the French BUC Working Group highlight the current interest of the BUC of PWR-MOx spent nuclear fuel for transport and storage. On top of that, design studies pointed out that the consideration of full BUC including fission products would enable a load increase in several fuel cycle devices (cask, storage pool). 


\section{Importance of fission products in PWR-MOx Burnup Credit}

The MOx fuel BUC is lower than the one of PWR-UOx fuels because of the conversion factor improvement due to the high ${ }^{240} \mathrm{Pu}$ content. Studies pointed out that the contribution of the 15 most absorbing, stable and non-volatile fission products selected (BUC-FPs : ${ }^{103} \mathrm{Rh},{ }^{149} \mathrm{Sm},{ }^{155} \mathrm{Gd},{ }^{151} \mathrm{Sm}$, $\left.{ }^{143} \mathrm{Nd},{ }^{133} \mathrm{Cs},{ }^{109} \mathrm{Ag},{ }^{152} \mathrm{Sm},{ }^{153} \mathrm{Eu},{ }^{99} \mathrm{Tc},{ }^{145} \mathrm{Nd},{ }^{101} \mathrm{Ru},{ }^{147} \mathrm{Sm},{ }^{95} \mathrm{Mo},{ }^{150} \mathrm{Sm}\right)$ represent more than a half of the total reactivity credit and $80 \%$ of the FPs credit (Table 1. and Fig.1) [2].

Table 1. Comparative values of PWR-UOx and MOx BUC ( $40 \mathrm{GWd} / \mathrm{t}_{\mathrm{HM}}, 1$ y CT)

\begin{tabular}{|c|c|c|}
\cline { 2 - 3 } \multicolumn{1}{c|}{} & PWR-UOx & PWR-MOx \\
\hline Actinides BUC & $19000 \mathrm{pcm}$ & $7550 \mathbf{~ p c m}$ \\
\hline 15 FPs BUC & $8400 \mathrm{pcm}$ & $8330 \mathrm{pcm}$ \\
\hline Total BUC & $\mathbf{2 7 4 0 0} \mathbf{~ p c m}$ & $\mathbf{1 5 8 8 0} \mathbf{~ p c m}$ \\
\hline
\end{tabular}

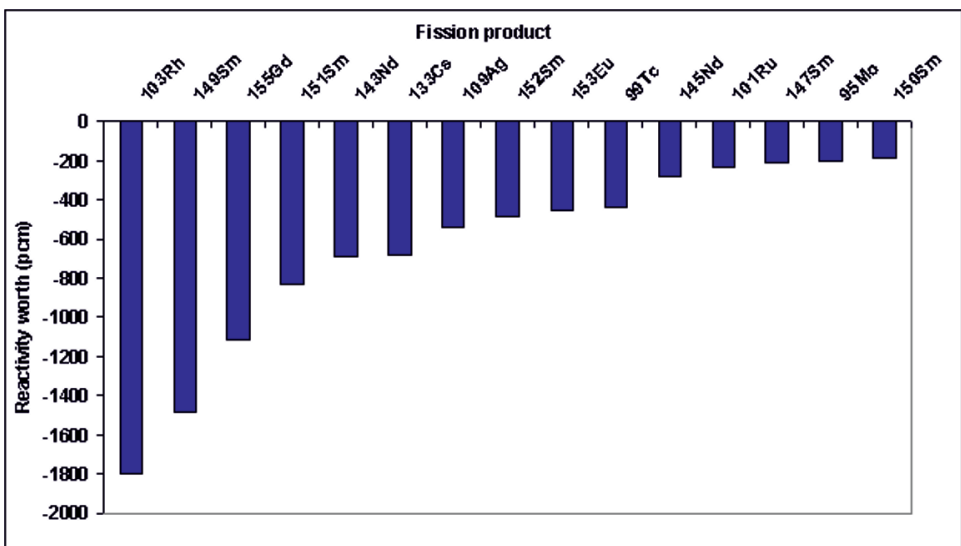

Fig. 1. BUC fission products reactivity worth contribution - $\left(40 \mathrm{GWd} / \mathrm{t}_{\mathrm{HM}}, 5 \mathrm{y} \mathrm{CT}\right)$.

In order to get a "best estimate" value of the $\mathrm{k}_{\text {eff }}$ and to meet USL constraint, calculation biases on FP inventory and individual reactivity worth should be considered in criticality studies [3].

\section{Inventory and individual reactivity worth biases evaluation}

In support of BUC studies, a specific experimental programme has been developed at Cadarache Centre in the framework of the CERES CEA-UKAEA co-operation [4], and later within the CEAAREVA collaboration [5]. This BUC programme is in particular composed of two kinds of experiments:

1. Chemical analyses and microprobe measurements of PWR-MOx spent fuel rods to obtain the spent fuel inventory (Actinides and FPs).

2. Reactivity worth measurements of the BUC nuclides by oscillation technique of specific separated-FP samples in the MINERVE reactor. 


\subsection{Assessment of inventory biases}

The BUC calculation route is based on the connection of the depletion code DARWIN [6] and the Criticality-safety Package CRISTAL [7]. Concerning the fuel inventory biases, trends in function of the burnup can be derived from the DARWIN-2.3 package qualification (using the JEFF-3.1.1 library [8] and the refined SHEM energy mesh).

\subsubsection{Post Irradiation Examination database and C/E comparison}

15 PWR-MOx fuel rods samples extracted from the French NPPs Saint Laurent and Dampierre were selected, with local burnup from $10 \mathrm{GWd} / \mathrm{t}_{\mathrm{HM}}$ to $60 \mathrm{GWd} / \mathrm{t}_{\mathrm{HM}}$. Considering representative central fuel rods samples reduces the uncertainties due to the environment in the context of nuclear data qualification.

Table 1. PIE database for inventory ICF in PWR-MOx applications

\begin{tabular}{|c|c|c|c|}
\hline NPP & $\begin{array}{c}\text { Burnup range } \\
\left(\mathbf{G W d} / \mathbf{t}_{\mathbf{H M}}\right)\end{array}$ & measurements & $\begin{array}{c}\text { Number of central fuel } \\
\text { rods samples }\end{array}$ \\
\hline Saint Laurent & 30 & $\mathrm{U}, \mathrm{Pu}, \mathrm{Nd}, \mathrm{Np}, \mathrm{Am}, \mathrm{Cm}, \mathrm{Cs}, \mathrm{Sm}, \mathrm{Eu}$, & 9 \\
\hline Dampierre & $10-58$ & $\begin{array}{c}\mathrm{U}, \mathrm{Pu}, \mathrm{Nd}, \mathrm{Np}, \mathrm{Am}, \mathrm{Cm}, \mathrm{Cs}, \mathrm{Sm}, \mathrm{Eu}, \\
\mathrm{Gd}, \mathrm{metallics}\end{array}$ \\
\hline
\end{tabular}

Using JEFF-3.1.1, concentrations of actinides and main BUC-FPs are well predicted as shown in Table 2 (particularly ${ }^{149} \mathrm{Sm},{ }^{133} \mathrm{Cs},{ }^{143} \mathrm{Nd}$ with $\mathrm{C} / \mathrm{E}$ biases less than $2 \%$ ).

Table 2. JEFF-3.1.1 calculation of PIEs in PWR-MOx assemblies

\begin{tabular}{|c|c|c|c|c|}
\hline \multirow{3}{*}{ Isotopic ratio } & \multicolumn{4}{|c|}{ C/E-1 $(\%) \pm \sigma(\%)$ MOx Dampierre 2} \\
\hline & \multicolumn{2}{|c|}{3 cycles $\mathbf{E 0 5}-40 \mathrm{GWd} / \mathrm{t}_{\mathrm{HM}}$} & \multicolumn{2}{|c|}{5 cycles $\mathbf{J} 08-57 \mathrm{GWd} / \mathrm{t}_{\mathrm{HM}}$} \\
\hline & JEF-2.2 & JEFF-3.1.1 & JEF-2.2 & JEFF-3.1.1 \\
\hline${ }^{234} \mathrm{U} /{ }^{238} \mathrm{U}$ & \multirow{10}{*}{$\begin{array}{l}\text { Not taken into } \\
\text { account in the } \\
\text { previous } \\
\text { interpretation } \\
\text { (results not } \\
\text { consistent because } \\
\text { of analysis } \\
\text { process issues) }\end{array}$} & $-2.2 \pm 1.0$ & $-3.6 \pm 1.2$ & $-1.7 \pm 1.2$ \\
\hline${ }^{235} \mathrm{U} /{ }^{238} \mathrm{U}$ & & $-0.6 \pm 1.6$ & $2.3 \pm 2.4$ & $0.5 \pm 2.6$ \\
\hline${ }^{236} \mathrm{U} /{ }^{238} \mathrm{U}$ & & $-2.2 \pm 1.4$ & $-5.7 \pm 1.2$ & $-2.2 \pm 0.9$ \\
\hline${ }^{238} \mathrm{Pu} /{ }^{238} \mathrm{U}$ & & $-4.6 \pm 1.4$ & $-4.4 \pm 1.0$ & $-2.9 \pm 1.5$ \\
\hline${ }^{239} \mathrm{Pu} /{ }^{238} \mathrm{U}$ & & $-5.1 \pm 1.7$ & $3.8 \pm 3.3$ & $1.3 \pm 1.1$ \\
\hline${ }^{240} \mathrm{Pu} /{ }^{238} \mathrm{U}$ & & $3.4 \pm 1.0$ & $0.8 \pm 1.4$ & $3.2 \pm 1.2$ \\
\hline${ }^{241} \mathrm{Pu} /{ }^{238} \mathrm{U}$ & & $-5.6 \pm 1.1$ & $0.2 \pm 1.5$ & $-1.5 \pm 1.2$ \\
\hline${ }^{242} \mathrm{Pu} /{ }^{238} \mathrm{U}$ & & $3.8 \pm 1.1$ & $-2.1 \pm 2.0$ & $1.4 \pm 0.9$ \\
\hline${ }^{241} \mathrm{Am} /{ }^{238} \mathrm{U}$ & & $-3.4 \pm 1.5$ & $6.7 \pm 2.3$ & $0.4 \pm 1.5$ \\
\hline${ }^{242 \mathrm{~m}} \mathrm{Am} /{ }^{238} \mathrm{U}$ & & $-9.5 \pm 2.3$ & $-20.3 \pm 3.2$ & $-4.4 \pm 1.7$ \\
\hline
\end{tabular}




\begin{tabular}{|c|c|c|c|}
\hline${ }^{243} \mathrm{Am} /{ }^{238} \mathrm{U}$ & $0.7 \pm 1.8$ & $1.0 \pm 2.2$ & $4.6 \pm 2.1$ \\
\hline${ }^{149} \mathrm{Sm} /{ }^{238} \mathrm{U}$ & $-5.3 \pm 1.6$ & $11.4 \pm 0.7$ & $1.6 \pm 5.1$ \\
\hline${ }^{133} \mathrm{Cs} /{ }^{238} \mathrm{U}$ & $1.3 \pm 1.8$ & $-0.7 \pm 1.8$ & $0.9 \pm 1.5$ \\
\hline${ }^{143} \mathrm{Nd} /{ }^{238} \mathrm{U}$ & $-0.9 \pm 1.6$ & $0.7 \pm 1.7$ & $-0.7 \pm 1.5$ \\
\hline
\end{tabular}

\subsubsection{Methodology}

Fuel inventory Isotopic Correction Factors (ICFs) values are deduced from the DARWIN-2.3 qualification $(\mathrm{C} / \mathrm{E}$ discrepancies values obtained for BUC isotopic concentration in each retained sample). Then, the methodology consists in the 4 following steps :

1. Determination of a linear trend of relative Calculation - Experiment discrepancies $(\mathrm{C}-\mathrm{E}) / \mathrm{E}$ in function of the burnup for each isotope using the generalized mean least squares method to take into account the uncertainty level of each point.

2. Determination of the total experimental uncertainty $1 \sigma$ by combination of the various uncertainty components : fuel and coolant/moderator temperatures during irradiation, initial $\mathrm{Pu}$ content, measurement uncertainty associated with the chemical assays, local burnup estimation and follow-up uncertainties for sensitive nuclides. It is showed that Actinide and FP ICFs values are mainly driven by the experimental uncertainties, particularly the burnup uncertainty component.

3. Penalization of the $(\mathrm{C}-\mathrm{E}) / \mathrm{E}$ bias at each burnup by the one-sided $95 \%$ confidence interval. For fissile isotopes, the penalized bias is $\Delta=(\mathrm{C}-\mathrm{E}) / \mathrm{E}-1.65 \sigma$ and $\Delta=(\mathrm{C}-\mathrm{E}) / \mathrm{E}+1.65 \sigma$ for the absorber isotopes. For the metallic FPs, the bias is determined using the impact of cumulative ${ }^{239} \mathrm{Pu}$ and ${ }^{241} \mathrm{Pu}$ fission yields, first source of calculation uncertainty on their concentrations.

4. Application of the $\mathrm{ICFs}=1 /(1+\Delta)$ (linear trend for ${ }^{239} \mathrm{Pu}$ and ${ }^{241} \mathrm{Pu}$ and unique conservative value for the other isotopes) to the calculated concentrations.

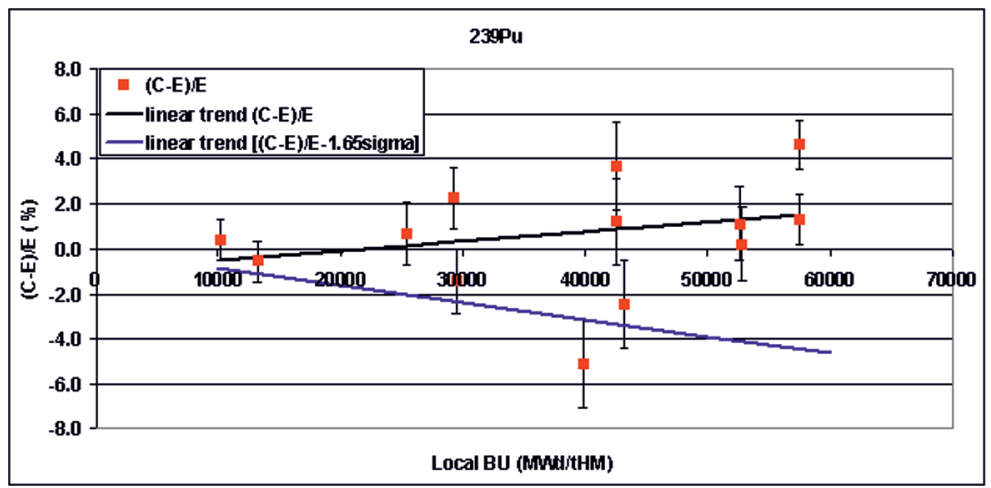

Fig. 2. Determination of the Isotopic Correction Factor associated with the ${ }^{239} \mathrm{Pu}$ concentration

\subsection{Individual reactivity worth bias}

There are not many experimental programs which involve BUC FPs in PWR-MOx spectrum and the access to their results is often restricted. Thanks to the BUC oscillation programme of separated FPs in the MINERVE reactor, calculation over experiment ratios can be accurately transposed to tendencies on the FPs integral cross sections. In 1998, samples of 12 separated FPs and 5 natural 
elements, Ag, Mo, Nd, Sm, Ru were oscillated in the R1MOX lattice corresponding to a PWR-MOx spectrum in the framework of the BUC experimental program. The introduction of the doped samples at the centre of the MINERVE core creates a flux variation which is detected by a boron chamber linked to a pilot rod. The pilot rod compensates this variation to maintain the critical state and its rotation angle is proportional to the reactivity of the inserted sample. The oscillation technique is well adapted to measure with accuracy low reactivity effects.

\subsubsection{Interpretation with the dedicated tool PIMS}

To reproduce the experiment by calculation without any numerical bias which could be inappropriately attributed to the nuclear data, a dedicated modular interpretation scheme, PIMS (Pile-Oscillation analysis tool for Improvement of cross Sections), fully validated against stochastic calculations, has been developed at CEA by D. Bernard and P. Leconte [9]. PIMS is based on the APOLLO2.8 deterministic code and on the recommendations from the reference SHEM-MOC calculation scheme for Light Water Reactor applications [10] and allow the use of exact perturbation theory to calculate the reactivity variation due to each oscillated sample.

The calculation over experiment ratios (Fig.2) show that, in a PWR-MOx spectrum, the isotopes ${ }^{109} \mathrm{Ag},{ }^{155} \mathrm{Gd},{ }^{143} \mathrm{Nd},{ }^{149,152} \mathrm{Sm}$ are well predicted with the European JEFF-3.1.1 library. Nevertheless, improvements may be needed in particular for ${ }^{145} \mathrm{Nd},{ }^{133} \mathrm{Cs},{ }^{99} \mathrm{Tc}$ and ${ }^{103} \mathrm{Rh}$. Concerning these resonant isotopes, we can notice an increase of the observed trends with the spectrum hardness by comparison with the results obtained in the MINERVE PWR-UOx lattice (R1UO2).

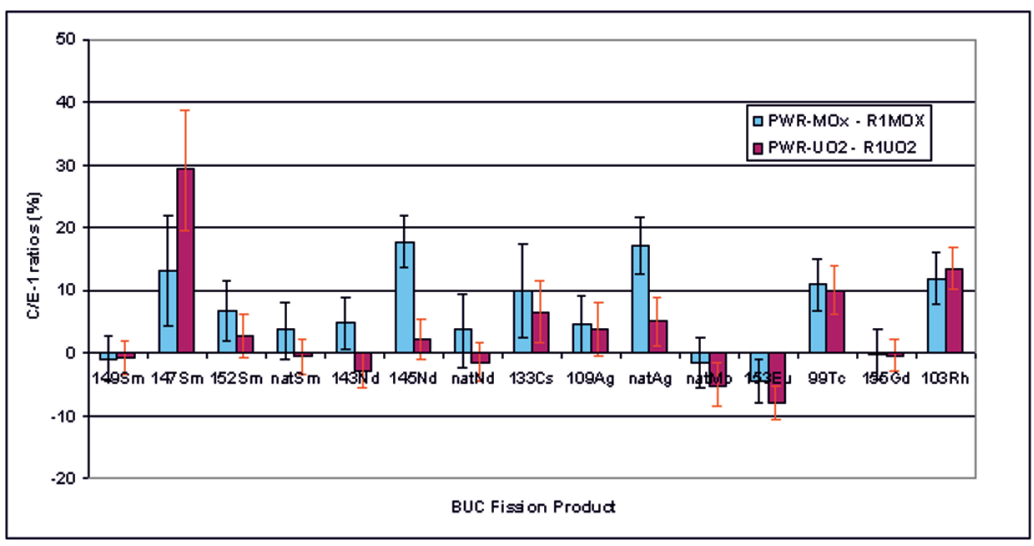

Fig. 3. C/E - 1 ratios (\%) of the BUC FPs in PWR-MOx and PWR-UOx lattices - uncertainty at $2 \sigma(\%)$

\subsubsection{Taking into account the individual reactivity worth in criticality-safety study}

The individual reactivity worth can be taken into account by the use of $\mathrm{k}_{\text {eff }}$ penalty terms by means of the Integral Experiment Methodology, based on experiment Representativity with respect of the studied application and on the re-estimation of nuclear data for the assessment of calculation biases and associated uncertainties [11]. A preliminary study with the dedicated tool RIB of the CRISTAL criticality-safety package gives a representativity factor $r=0.94$ of the MINERVE ${ }^{155} \mathrm{Gd}$ worth with respect to FP-BUC poisoning in a PWR-MOx assembly. The use of such a methodology requires the elaboration and introduction in JEFF-3.1.1 evaluation of the missing covariance matrices for actinides and each of the 15 BUC FPs. The actual ${ }^{235} \mathrm{U}$ covariance matrix associated with the JEFF3.1.1 has already been derived from targeted clean integral experiments using the RDN process of 
nuclear data re-evaluation (rigorous non-linear regression method) [12]. Covariance matrices, obtained from ND differential measurements or expert advice, are already available for BUC nuclides : COMAC (COvariance MAtrices from Cadarache) [13], COMMARA, ENDF BVII , SCALE-6, TENDL. However, we will use the MINERVE integral measurements in order to infer realistic JEFF-3.1.1 covariance matrices for BUC FPs.

\section{Conclusion}

An important issue of LWR-MOx BUC methodology is the evaluation and the way of taking into account the biases on FPs inventory and individual reactivity worth calculation in criticality-safety studies. In order to support the implementation of such a methodology, specific experimental programs were carried out by CEA. Concerning the fuel inventory biases, trends in function of the burnup can be derived from the DARWIN-2.3 package qualification. Thanks to the BUC oscillation program of separated FPs in the MINERVE reactor and the fully validated scheme PIMS, C/E biases can be transposed to tendencies on integral FPs cross sections; the precision of the reactivity worth predicted with JEFF-3.1.1 is highlighted for important BUC FPs : ${ }^{149} \mathrm{Sm}$ and ${ }^{155} \mathrm{Gd}(<2 \%)$, ${ }^{143} \mathrm{Nd}$, ${ }^{152} \mathrm{Sm},{ }^{109} \mathrm{Ag}$ and ${ }^{153} \mathrm{Eu}(<5 \%)$. However, some improvements may be needed to correct the overestimation of ${ }^{145} \mathrm{Nd},{ }^{133} \mathrm{Cs}$ and ${ }^{103} \mathrm{Rh}$ resonance integral.

The use of the Integral Experiment Methodology confirms the good representativity of the MINERVE experiments for BUC industrial application. On the basis of existing best-estimate covariance matrices and the RDN processing of MINERVE experimental results, missing JEFF3.1.1 covariances will be derived and introduced in the RIB tool, in order to obtain biases and associated uncertainties in JEFF-3.1.1-based safety-criticality calculations.

\section{References}

1. A. Santamarina, "Burnup Credit implementation in spent fuel management", FJSS'98, CEA Cadarache, France, Augustus, 17-26 (1998)

2. B. Roque, A. Santamarina , "Burnup Credit in LWR-MOX assemblies", Proc. Int. Conf. on Nuclear Criticality Safety ICNC'99, Vol 4 p1666, Versailles, France, September 20-24 (1999)

3. A. Barreau, B. Roque, A. Santamarina, C. Venard, "Recent advances in French validation program and derivation of the acceptance criteria", Technical Meeting on Advances in Applications of Burnup Credit, IAEA-TECDOC-CD-1547, London, August 29-Sept 2 (2005)

4. A. Santamarina \& al. , "Experimental validation of Burnup Credit calculation by Reactivity Worth Measurements in MINERVE Reactor", Proc. Int. Conf. on Nuclear Criticality Safety (ICNC'95), Albuquerque, New Mexico, USA, September 17-21 (1995)

5. A. Santamarina, N. Thiollay, C. Heulin, J.P. Chauvin, "The French Experimental Programme on Burnup Credit", Proc. Top. Meeting on Criticality Safety Challenges, Chelan (WA), USA, September 7-11 (1997)

6. L. San Felice \& al. , "Experimental validation of the DARWIN-2.3 package for fuel cycle applications", Proc. Int. Conf. (PHYSOR 2012), Knoxville, USA, April 15-20, 2012

7. J.M Gomit \& al., "CRISTAL Criticality package : twelve years later and new features", Proc. Int. Conf. on Nuclear Criticality Safety (ICNC 2011), Edinburgh, UK, September 19-22 (2011)

8. A. Santamarina \& al., "The JEFF-3.1.1 Nuclear Data Library," JEFF Report 22, OECD 2009, NEA No.6807

9. A. Gruel, P.Leconte, D. Bernard, P. Archier, G. Noguère, "Interpretation of Fission Product Oscillations in the MINERVE reactor, from Thermal to Epithermal Spectra", Nucl. Sci. and Eng, 169, 229-224 (2011)

10. A. Santamarina, D. Bernard, P. Blaise, L. Erradi, R. Letellier, C. Vaglio, J-F. Vidal, "APOLLO2.8 : a validated code package for PWR calculations," Proc. Int. Conf. Advances in Nuclear Fuel Management ANFM-IV, Hilton Head Island (SC), USA, April 12-15 (2009). 
11. C. Venard, A. Santamarina, A. Leclainche, C. Mounier, "The RIB tool for the determination of computational bias and associated uncertainty in the CRISTAL criticality-safety package", Proc. Int. Conf. NCSD 2009, Shilo Inn, Richland, Washington, USA, September 13-17 (2009)

12. A. Santamarina, D. Bernard, N. Dos Santos, O. Leray, C. Vaglio, L. Leal, "Re-estimation of Nuclear Data and JEFF-3.1.1 uncertainty calculation", Proc. Int. Conf. PHYSOR 2012, Knoxville, USA, April 15-20 (2012)

13. De Saint Jean, P. Archier, G. Noguere, O. Litaize, C. Vaglio, D. Bernard, O. Leray, "Estimation of multi-group cross section covariances of ${ }^{238,235} \mathrm{U},{ }^{239} \mathrm{Pu},{ }^{241} \mathrm{Am},{ }^{56} \mathrm{Fe}$ and ${ }^{23} \mathrm{Na}$, Proc. Int. Conf. PHYSOR 2012, Knoxville, USA, April 15-20 (2012) 